\title{
Neuropsychological impairments in chronic fatigue syndrome, multiple sclerosis, and depression
}

\author{
John DeLuca, Susan K Johnson, Dawn Beldowicz, Benjamin H Natelson
}

\begin{abstract}
To examine the degree and nature of cognitive impairments in chronic fatigue syndrome, a comprehensive neuropsychological battery was given to patients with chronic fatigue syndrome, multiple sclerosis, depressed patients, and healthy controls. The battery included tests of attention and concentration, information processing speed, verbal and visual memory, intellectual ability, and concept formation. Measures of depression and anxiety were also obtained. The chronic fatigue syndrome group did not differ from the depressed group in overall neuropsychological performance, but differed from the multiple sclerosis and control groups. The most significant impairment was in information processing speed in the chronic fatigue syndrome group. Depression and anxiety were not related to neuropsychological performance. The influence of reduced information processing on other areas of cognition is discussed.
\end{abstract}

(F Neurol Neurosurg Psychiatry 1995;58:38-43)

Keywords: neuropsychological impairments; multiple sclerosis; depression; fatigue syndrome

Kessler Institute for Rehabilitation, West Orange, New Jersey, USA

Department of

Research and

Psychology

J DeLuca

S K Johnson

UMDNJ-New Jersey

Medical School,

Newark, New Jersey,

USA

Department of

Physical Medicine and

Rehabilitation

J DeLuca

S K Johnson

Department of

Neurosciences

J DeLuca

D Beldowicz

D Beldowicz

Correspondence to:

Dr John DeLuca, Kessler

Dr John DeLuca, Kessler

Institiute for Rehabilitation

1199 Pleasant Valley Way

West Orange, NJ 07052
USA.

Received 15 March 1994

and in revised form

13 June 1994.

Accepted 20 July 1994
Chronic fatigue syndrome is a disabling illness that primarily afflicts middle aged, white women. The illness is defined as new onset of severe fatigue without any known medical cause $^{1}$; accompanying symptoms are rheumatological (for example, myalgias, joint pain), infectious (for example, sore throat, fever, swollen lymph nodes), and neuropsychiatric (for example, headache, weakness, depression, cognitive disturbance).

There have been few published reports aimed at examining cognition in patients with chronic fatigue syndrome. Early studies had methodological drawbacks, particularly the absence of a control group. More recent studies have generally yielded subtle, but inconsistent findings. For instance, verbal memory impairments in chronic fatigue syndrome or myalgic encephalomyelitis (chronic fatigue syndrome as defined in the United Kingdom) have been found by some ${ }^{23}$ but not others, ${ }^{45}$ or have been related to depression. ${ }^{6}$ Similarly, both impaired ${ }^{4}$ and unimpaired ${ }^{2}$ visual memory have been reported in chronic fatigue syndrome and myalgic encephalomyelitis. Discrepancies have also been found in multi- modal sensory evoked potentials and auditory event related cognitive potentials. One study ${ }^{7}$ found impaired auditory cognitive potentials (N2 and P3) compared with controls, which were interpreted as reflecting impairments in attention and speed of information processing in myalgic encephalomyelitis. Another group, however, did not find differences between chronic fatigue syndrome and controls in the visual domain. ${ }^{8}$ Reaction times were significantly prolonged in the chronic fatigue syndrome and myalgic encephalomyelitis groups of both studies.

DeLuca et $a l^{9}$ examined patients with chronic fatigue syndrome, multiple sclerosis, and healthy controls on the paced auditory serial addition test (PASAT), a test of complex auditory information processing. They found that both the chronic fatigue syndrome and multiple sclerosis groups scored significantly below controls on the PASAT, but did not differ from each other. Performance on the PASAT was not significantly correlated with depression. DeLuca et $a l^{9}$ suggested that patients with chronic fatigue syndrome have difficulty in the simultaneous processing of multiple elements of complex information. They hypothesise that the perceived memory impairments in those with chronic fatigue syndrome may actually be a reflection of impaired information processing rather than memory itself. Partial support for this contention has been provided in recent reports. ${ }^{35}$

Given the paucity of objective data and the inconsistencies in the data that do exist, the present study was conducted to assess a broad range of neuropsychological functioning in persons with chronic fatigue syndrome. Patients with chronic fatigue syndrome were compared with patients who had multiple sclerosis, patients with major depressive disorder or dysthymia, and healthy controls. The multiple sclerosis group was chosen so that performance of the chronic fatigue syndrome group could be compared with a population presenting with a symptom cluster similar in many ways to patients with chronic fatigue syndrome (for example, impairments in information processing, learning and memory, fatigue, depression), but of known organic aetiology. The addition of a depressed group is critical as patients with chronic fatigue syndrome often manifest symptoms of depression, and given the current controversy over whether cognitive symptoms in chronic fatigue syndrome are due solely to depression. ${ }^{6}$ Finally, patients with chronic fatigue syndrome in the present study were selected 
more stringently regarding premorbid psychiatric state, disease duration, and severity than in our prior work. ${ }^{59}$

\section{Methods}

PATIENTS

Patients who met the published case definition for chronic fatigue syndrome ${ }^{10}$ were included in the study. Additional inclusion criteria were: (1) patients had to have been diagnosed within the past four years; (2) symptoms of at least moderate severity had to be present at the time of intake; (3) there was no history of a psychiatric disorder in the five years before the diagnosis of chronic fatigue syndrome or history of substance abuse at any time as determined by the diagnostic interview schedule; and (4) there had to be no history of loss of consciousness greater than five minutes.

Twenty six patients with chronic fatigue syndrome were compared with age, sex, and education matched groups consisting of 12 patients with multiple sclerosis, 14 depressed patients, and 20 healthy controls. No significant differences were found among the groups in mean age (chronic fatigue syndrome group $=34.3$ (SEM 1.8); healthy group = $37 \cdot 0(2 \cdot 4)$; multiple sclerosis group $=36 \cdot 0$ (3.0); depressed group $=39 \cdot 7(2 \cdot 1) ; F(3,68)$ $=1.02, \mathrm{p}<0.38)$ or in mean years of education (chronic fatigue syndrome group $=14 \cdot 6$ $(0.4)$; healthy group $=15.5(0.6)$; multiple sclerosis group $=14.2(0.8)$; depressed group $=15.8(0.6) ; \quad F(3,68)=1.5, \quad \mathrm{p}<0.20)$. Patients with multiple sclerosis were all clinically stable, were diagnosed with clinically definite multiple sclerosis, ${ }^{11}$ and had an expanded disability status scale (EDSS) of 2.5 or less. This cut off was specifically selected to contrast patients with multiple sclerosis and "mild" physical symptoms with patients with chronic fatigue syndrome. The mean EDSS for the multiple sclerosis group was $1 \cdot 2$ (SEM 0.22 ). Current affective or anxiety disorders were not a cause for exclusion for patients with chronic fatigue syndrome or multiple sclerosis. ${ }^{10}$ Healthy subjects and patients with depression were recruited from local therapists and by advertising in the local community, and were paid for their participation. Healthy subjects and depressed patients who reported no medical problems and were taking no medication other than birth control pills were included. Depressed patients had to be diagnosed with either major depression or dysthymia according to the DIS III-R criteria. Fatigue was assessed by the Krupp fatigue scale. ${ }^{12}$ The mean level of fatigue in the chronic fatigue syndrome group (57.2 (SEM $1 \cdot 0)$ ) was significantly increased relative to all other groups $(p<0.001)$. The depressed $(32.5(3.8))$ and multiple sclerosis (35.6 $(6 \cdot 1))$ groups did not significantly differ from each other, but both differed significantly from controls $(17 \cdot 1(2 \cdot 3) ; \mathrm{p}<0 \cdot 01)$. ropsychological tests, administered and scored in accordance with published procedures. The tests consisted of the digit span subtest of the WAIS-R ${ }^{13}$ - a test of "auditory span" of attention; paced auditory serial addition test (PASAT) - a test of information processing speed; trail making test-a test of visuomotor scanning and concentration; booklet category test (BCT) - a test of complex problem solving and conceptual reasoning; vocabulary, arithmetic, similarities, and block design, subtests of the WAIS-R - tests of intellectual functions; Rey complex figure test-a test of visual memory; California verbal learning test (CVLT) - a test of verbal list learning and memory; and the logical memory subtest of the Wechsler memory scale revised ${ }^{14}$-a test of verbal paragraph recall. The Beck depression inventory (BDI) ${ }^{15}$ and the state-trait anxiety scale (STAI) ${ }^{16}$ were also given. In addition, a metamemory questionnaire $^{17}$ and a cognitive problems checklist were given to all subjects. Based on factor analysis, the metamemory questionnaire is divided into four primary areas of memory: attention/prospective memory, retrograde memory, historic/overload memory, and anterograde memory. The cognitive problems checklist was used to quantify the cognitive complaints that patients with chronic fatigue syndrome often have. It consisted of a 1-5 Likert scale, where subjects rated their difficulties in the areas of attention, concentration, memory, and reasoning. The tests and questionnaires were given in one session lasting about 150 minutes.

\section{DATA ANALYSIS}

Planned comparisons of non-orthogonal contrasts were performed between the clinical groups and the healthy controls. With these tests, it is not necessary to perform an overall omnibus test of significance before testing the planned comparisons. ${ }^{18}$ Dunnett's test was used to compare each of the clinical groups with the healthy group. Contrasts between the various clinical groups were performed with the Dunn's multiple comparisons procedure. Fatigue data were analysed by Wilcoxon rank test. ${ }^{18}$

Because cognitive impairments in multiple sclerosis are well documented, ${ }^{19}$ one tailed Dunnett's tests comparing multiple sclerosis with controls were performed. Also, because of the previous findings of impaired PASAT performance in patients with chronic fatigue syndrome and multiple sclerosis, ${ }^{9}$ a one tailed Dunnett's test for contrasts involving a control mean with all clinical groups was performed for the PASAT results. All other contrasts were analysed by a two tailed procedure.

\section{Results}

\section{SUBJECTIVE COMPLAINTS}

Overall, patients with chronic fatigue syndrome had the broadest degree of subjective complaints of cognitive impairment compared with the other groups (table 1). Subjective 
Table 1 Subjective data for the clinical and control groups (meaan (SEM))

\begin{tabular}{|c|c|c|c|c|}
\hline & CFS & Healthy & $M S$ & $D E P$ \\
\hline $\begin{array}{l}\text { CPC questionnaire data: } \\
\text { Attention } \\
\text { Concentration } \\
\text { Memory } \\
\text { Reasoning }\end{array}$ & $\begin{array}{l}3 \cdot 1(0 \cdot 21)^{\star \star} \dagger \\
3 \cdot 2(0 \cdot 19) \dagger \\
3 \cdot 2(0 \cdot 20)^{\star \star} \\
3 \cdot 1(0 \cdot 22) \dagger \ddagger\end{array}$ & $\begin{array}{l}1 \cdot 1(0 \cdot 08) \\
1 \cdot 1(0 \cdot 18) \\
1 \cdot 2(0 \cdot 12) \\
1 \cdot 1(0 \cdot 08)\end{array}$ & $\begin{array}{l}1.9(0.35) \\
1.9(0.23) \\
2.2(0.25)^{\star \star} \\
1.6(0.26)\end{array}$ & $\begin{array}{l}2.3(0.29)^{\star \star} \\
2 \cdot 6(0.25) \dagger \\
2 \cdot 2(0.30)^{\star} \\
1.8(0.23)\end{array}$ \\
\hline $\begin{array}{l}\text { Metamemory questionnaire data: } \\
\text { Attention/prospective } \\
\text { Retrograde } \\
\text { Anterograde } \\
\text { Biographical }\end{array}$ & $\begin{array}{l}2 \cdot 7(0.2) \dagger \ddagger \\
1.8(0 \cdot 2) \star \\
2.3(0.2) \dagger \\
1.3(0.2)\end{array}$ & $\begin{array}{l}1 \cdot 4(0 \cdot 1) \\
1 \cdot 2(0 \cdot 1) \\
1 \cdot 2(0 \cdot 1) \\
1 \cdot 1(0 \cdot 0)\end{array}$ & $\begin{array}{l}1.7(0.1) \\
1.3(0.1) \\
1.6(0.2) \\
1.1(0.1)\end{array}$ & $\begin{array}{l}2 \cdot 1(0 \cdot 2) \dagger \\
1 \cdot 6(0 \cdot 2) \\
1 \cdot 8(0 \cdot 2) \\
1 \cdot 1(0 \cdot 1)\end{array}$ \\
\hline
\end{tabular}

Table 2 Performance of clinical and control groups on psychological measures (mean (SEM))

\begin{tabular}{lllll}
\hline & CFS & Healthy & $M S$ & DEP \\
\hline Beck depression inventory & $14 \cdot 5(1 \cdot 6)^{\star}$ & $2 \cdot 1(0 \cdot 6)$ & $8 \cdot 7(2 \cdot 3) \dagger$ & $18 \cdot 8(2 \cdot 7)^{\star}$ \\
State anxiety inventory & $39 \cdot 8(2 \cdot 7)^{\star}$ & $26 \cdot 8(1 \cdot 4)$ & $29 \cdot 4(1 \cdot 8) \ddagger$ & $43 \cdot 3(3.8)^{\star}$
\end{tabular}

${ }^{\star} \mathrm{p}<0.01 v$ healthy group.

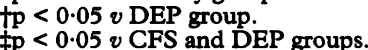

Ap $<0.05 v$ CFS and DEP
Abbreviations as for table 1 .

Table 3 Performance of clinical and control groups on tests of attention, concentration, and information processing (mean (SEM))

\begin{tabular}{lllll}
\hline & CFS & Healthy & $M S$ & DEP \\
\hline PASAT total & $124(6 \cdot 1)^{\star}$ & $144(5 \cdot 1)$ & $130(6 \cdot 7)$ & $136(8 \cdot 1)$ \\
Trails A & $27.5(1 \cdot 8)$ & $27.5(2 \cdot 1)$ & $27.9(7 \cdot 8)$ & $27 \cdot 8(2 \cdot 4)$ \\
Trails B & $55 \cdot 8(3.0)$ & $52 \cdot 8(3.7)$ & $68 \cdot 6(7 \cdot 8)$ & $62 \cdot 0(5 \cdot 8)$ \\
Digit span & $17.0(1.0)$ & $18 \cdot 2(0.8)$ & $16.5(1 \cdot 3)$ & $17.5(1 \cdot 1)$ \\
\hline
\end{tabular}

$\star \mathrm{p}<0.05$.

PASAT = Paced auditory serial addition test. Other abbreviations as for table 1.

Table 4 Performance of clinical and control groups on tests of memory (mean (SEM))

\begin{tabular}{|c|c|c|c|c|}
\hline & CFS & Healthy & MS & $D E P$ \\
\hline \multicolumn{5}{|l|}{ Rey figure: } \\
\hline Copy & $66 \cdot 3(1 \cdot 1)$ & $69.0(0.6)$ & $68 \cdot 2(1 \cdot 2)$ & $67 \cdot 2(1 \cdot 2)$ \\
\hline Immediate recall & $34.9(2 \cdot 8)$ & $43.7(1.9)$ & $37 \cdot 1(3 \cdot 4)$ & $33 \cdot 5(4 \cdot 0)$ \\
\hline Delay recall & $34.5(2 \cdot 8)$ & $40.9(2 \cdot 1)$ & $37.7(3.6)$ & $31.8(4.0)$ \\
\hline Forgetting & $0.99(0.04)$ & $0.89(0.05)$ & $1.01(0.04)$ & $0.98(0.06)$ \\
\hline \multicolumn{5}{|l|}{ Logical memory: } \\
\hline Immediate recall & $24 \cdot 3(1 \cdot 2)$ & $28.5(1.5)$ & $22 \cdot 8(1 \cdot 4)^{\star}$ & $25 \cdot 1(2 \cdot 0)$ \\
\hline Delay recall & $20 \cdot 4(1 \cdot 3)$ & $25.0(1.8)$ & $18 \cdot 0(2 \cdot 1)^{\star}$ & $20 \cdot 3(2 \cdot 1)$ \\
\hline $\begin{array}{l}\text { Forgetting } \\
\text { CVLT: }\end{array}$ & $0.83(0.04)$ & $0.86(0.03)$ & $0.79(0.06)$ & $0.78(0.04)$ \\
\hline \multicolumn{5}{|l|}{ CVLT: } \\
\hline (trials 1-5) & $34.6(2 \cdot 8)^{\star \star}$ & $49 \cdot 0(2 \cdot 2)$ & $42 \cdot 2(3 \cdot 2)$ & $38 \cdot 1(3 \cdot 6)$ \\
\hline List A trial 1 & $6.8(0.4)^{\star \star}$ & $8.8(0.4)$ & $7.9(0.5)$ & $7.4(0.4)$ \\
\hline List A trial 5 & $12 \cdot 1(0.4)^{\star}$ & $14.0(0.4)$ & $12.5(0.5)$ & $12 \cdot 1(0 \cdot 7)^{\star}$ \\
\hline List B & $6 \cdot 8(0.5)$ & $7 \cdot 5(0.4)$ & $7 \cdot 0(0 \cdot 4)$ & $7 \cdot 1(0 \cdot 7)$ \\
\hline $\begin{array}{l}\text { SD free recall } \\
\text { SD cued recall }\end{array}$ & $9.8(0.6)^{\star}$ & $12 \cdot 3(0 \cdot 6)$ & $9 \cdot 7(0 \cdot 7)^{\star}$ & $10 \cdot 8(0.9)$ \\
\hline SD cued recall & $11 \cdot 3(0 \cdot 5)$ & $13 \cdot 1(0 \cdot 6)$ & $12 \cdot 1(0 \cdot 7)$ & $12 \cdot 2(0 \cdot 7)$ \\
\hline LD free recall & $10.6(0.6)^{\star}$ & $12.9(0.6)$ & $11.9(0.8)$ & $11 \cdot 0(0.8)$ \\
\hline $\mathrm{LD}$ cued recall & $11.8(0.5)$ & $13.5(0.6)$ & $12 \cdot 4(0 \cdot 6)$ & $12 \cdot 0(0 \cdot 7)$ \\
\hline Recognition & $13.5(0.6)$ & $15 \cdot 0(0.3)$ & $14 \cdot 1(0 \cdot 6)$ & $14 \cdot 4(0.5)$ \\
\hline
\end{tabular}

$\star p<0.05 ;{ }^{\star \star} p<0.01 v$ healthy controls.

CVLT = California verbal learning test. Other abbreviations as for table 1 .

complaints of attention differed significantly across groups $(F(3,57)=15.7, \mathrm{p}<0.001)$, with the chronic fatigue syndrome group expressing a significantly greater degree of impairment than either the multiple sclerosis or healthy control groups. The depressed group differed only from controls. For concentration $(F(3,57)=27.0, \mathrm{p}<0.001)$, the chronic fatigue syndrome and depressed groups did not differ from each other, but both differed from the multiple sclerosis group and healthy controls. All three clinical groups showed increased complaints of memory relative to controls $(F(3,57)=18 \cdot 0, \mathrm{p}<$
0.001 ). The chronic fatigue syndrome group expressed significantly greater difficulties. in reasoning ability than any other groups ( $F$ $(3,57)=20 \cdot 0, \mathrm{p}<0.0001)$.

On the metamemory questionnaire, the chronic fatigue syndrome group expressed significantly more subjective difficulties than any of the other three groups on the attention/prospective memory factor $(F(3,68)=$ $16.1, p<0.001)$. The depressed group differed from both the multiple sclerosis and healthy groups. For retrograde memory, the only significant difference was between the chronic fatigue syndrome $v$ healthy group ( $F$ $(3,68)=3 \cdot 0, p<0 \cdot 04)$. On the anterograde memory factor, the chronic fatigue syndrome group differed significantly from the multiple sclerosis and healthy groups, but not from the depressed group $(F(3,68)=8.5, \mathrm{p}<0.001)$. No differences were seen across groups for the historic/overload memory factor $(F(3,68)=$ $1 \cdot 4, p=0 \cdot 24)$.

DEPRESSION AND ANXIETY

On the STAI (table 2), the chronic fatigue syndrome and depressed groups showed significantly higher scores than either the multiple sclerosis or healthy control groups, which themselves did not differ significantly ( $F$ $(3,68)=16.4, p<0.001)$. The mean performance by the chronic fatigue syndrome group was not, however, in the clinically impaired range. ${ }^{22}$ The mean Beck depression inventory scores for the chronic fatigue syndrome and depressed groups were significantly higher than the healthy control group $(F(3,68)=$ $16.4, p<0.001)$. Whereas the multiple sclerosis group scored significantly lower than the depressed group on the Beck depression inventory, they did not differ statistically from controls.

\section{ATTENTION AND CONCENTRATION}

Table 3 gives the mean scores for attention and concentration. There were no statistically significant differences across the four groups in digit span performance $(F(3,68)=0.46$, p $<0.71)$, trails A $(F(3,68)=0.007, \mathrm{p}=0.99)$ or trails $\mathrm{B}(F(3,68)=1 \cdot 9, \mathrm{p}=0 \cdot 12)$. On the PASAT, the mean number of correct responses was significantly lower in the chronic fatigue syndrome than in controls but did not differ significantly from the multiple sclerosis or depressed groups. Mean PASAT performance in both the multiple sclerosis and depressed groups did not differ statistically from healthy controls.

To examine the potential influence of anxiety on PASAT performance in patients with chronic fatigue syndrome, a median split of the STAI of the group was performed. The mean total PASAT score for the high and low STAI groups was $131 \cdot 1$ (SEM 9.2) and $117 \cdot 0$ (SEM 8.0). This difference between the two groups did not differ statistically $(F(1,24)=$ $1 \cdot 35, p=0 \cdot 26)$. To examine the influence of depression on PASAT performance, mean PASAT scores of the chronic fatigue syndrome group were divided into high (>13) and low $(\leqslant 12)$ Beck depression inventory 
scores ( $\mathrm{n}=13$ for each group). Mean PASAT total scores for the high $(119 \cdot 3(8 \cdot 5))$ and low (128.7 (9.0)) Beck depression inventory groups did not differ and significantly ( $F$ $(1,24)=0.57, \mathrm{p}=0.45)$.

\section{MEMORY}

Table 4 provides the mean scores on tests of memory. No statistically significant differences were found between any of the groups in the amount of material recalled on the Rey complex figure in either the immediate $(F$ $(3,68)=2 \cdot 4, \mathrm{p}=0.07)$ or delayed $(F(3,68)=$ $1.5, \mathrm{p}=0.20)$ conditions. Thus visual memory performance was not impaired in any of the clinical groups evaluated.

For verbal memory, the chronic fatigue syndrome and depressed groups did not differ from each other or from the healthy control group in immediate and delayed recall on logical memory. Only the multiple sclerosis group recalled significantly fewer elements on logical memory in both the immediate and delayed conditions than controls. When delayed recall was measured as a percentage of the amount of information initially learned, no statistically significant difference was found between the multiple sclerosis and control conditions. This suggests that the memory difficulty found in the multiple sclerosis group was in initial learning of material, and that what information was initially learned was adequately retrieved.

On a measure of the amount of information learned across the five trials (trials 1-5) of the CVLT, the chronic fatigue syndrome group recalled a mean of 34.6 words, which was significantly below the mean of 49.0 words for the healthy controls, suggesting difficulty in acquiring the material $(F(3,68)=5 \cdot 2, p=$ 0.01 ). Compared with controls, the chronic fatigue syndrome group recalled significantly fewer words both during the initial learning trial (list A trial 1) $(F(3,68)=4.9, \mathrm{p}=0.01)$ and the final learning trial (list A trial 5$)(F$ $(3,68)=3.7, \quad p=0.01)$. Although the depressed group and healthy controls did not differ in the amount of words recalled during list A trial 1, the depressed group recalled significantly fewer words $(12 \cdot 0)$ than controls by list A trial 5. The multiple sclerosis group did not differ from the healthy control group in the amount of information learned.

With respect to recall from long term storage, the chronic fatigue syndrome group

Rating of overall neuropsychological impairment for each group (mean $(S E M)) . S I R=$ summed impairment rating. $C F S=$ chronic fatigue syndrome; $M S=$ fatigue syndrome; $M S=$
multiple sclerosis; $D E P=$ depressed group.

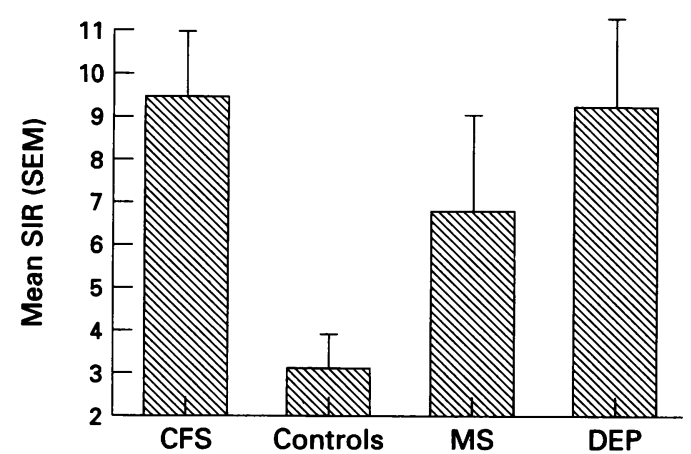

recalled significantly fewer words during both the immediate $(F(3,68)=3.2, \mathrm{p}=0.02)$ and delayed $(F(3,68)=2 \cdot 6, \mathrm{p}<0.05)$ free recall conditions than the healthy controls. No difference between the chronic fatigue syndrome and control groups were found in the cued recall conditions. The difference between chronic fatigue syndrome and controls in free but not cued recall may suggest difficulties in retrieval from long term storage in the chronic fatigue syndrome group. Given that the patients with chronic fatigue syndrome learned significantly fewer words than controls, a measure of the amount of information recalled relative to what was initially learned might be a more representative analysis of free and cued recall effects. Thus free and cued recall were analysed as a percentage of the information recalled on list A trial 5 . In this analysis, no differences were found between patients with chronic fatigue syndrome and healthy controls in the relative amount of information recalled during both the free $(t=-1.4, \mathrm{p}<0.15)$ and cued $(t=-1 \cdot 2$, $\mathrm{p}<0.25)$ recall conditions. During free recall, the chronic fatigue syndrome group recalled $81 \%$ of that initially learned compared with $87 \%$ in healthy controls. During cued recall, $87 \%$ and $92 \%$ recall was observed for the chronic fatigue syndrome group and healthy controls respectively. The chronic fatigue syndrome and healthy control groups did not differ during recognition memory testing.

Overall, the multiple sclerosis group did not differ from healthy controls on the CVLT measures of acquisition, recall, or recognition. The only exception was the significantly reduced short delay free recall in the multiple sclerosis group compared with controls.

\section{HIGHER COGNITIVE FUNCTIONS}

There were no statistically significant differences on the four tests of intellectual functions from the WAIS-R, or on the booklet category test. Thus higher level cognitive functioning did not differ between any of the four groups.

\section{OVERALL GROUP PROFILES}

As well as contrasting the mean performance on each neuropsychological measure across groups, it was also of interest to obtain a summary measure of overall neuropsychological impairment. An impairment rating (IR) was calculated based on SDs from the mean performance of the healthy control group. The IR was calculated as follows: scores for each test measure within $1 \mathrm{SD}$ of the control group were assigned an IR of 0 ; scores between 1 and 2 SDs below the control group were assigned an IR of 1 ; scores between 2 and 3 SDs below that of controls were assigned an IR of 2; and scores greater than 3 SDs received an IR of 3. Raw scores for each of the 21 test measures were transformed into an IR score for each subject. The IRs were then summed to obtain a summed IR (SIR) of overall performance for each subject. The SIR served as the dependent variable for a 1 way analysis of variance (ANOVA) contrasting the 
four groups. The mean SIR (figure) for the chronic fatigue syndrome group was 9.5 ( $\operatorname{SEM}=1.6)$, for the depressed group 9.2 (SEM 0.9), for the multiple sclerosis group 6.8 (SEM 2.3), and for the healthy controls $3.2(\operatorname{SEM} 2 \cdot 0)(F(3,71)=3 \cdot 45, \mathrm{p}=0.021)$. Significant differences $(F(3,68)=3.4, \mathrm{p}=$ 0.02 ) were found between the healthy controls and both the chronic fatigue syndrome $(p<0.05)$ and depressed $(p<0.05)$ groups in overall neuropsychological performance.

\section{Discussion}

The results of this study replicate and extend our earlier work ${ }^{9}$ suggesting that patients with chronic fatigue syndrome show a selective impairment in information processing of complex auditory material. One difficulty with this interpretation is the likelihood that the auditory (PASAT) and visual (trail making test) tasks used in the present study may not be equally difficult. Only auditory and visual tasks equated for difficulty will satisfactorily answer whether there is a general or selective (auditory) information processing deficit in chronic fatigue syndrome.

Another potential explanation for the difference in performance between the PASAT and the trail making test among patients with chronic fatigue syndrome may reflect differences in the specific component of "attention" assessed. Intact performance on the trail making test suggests that patients with chronic fatigue syndrome show intact visuomotor scanning ability, ${ }^{20}$ whereas impaired PASAT reflects impaired sustained selective processing of information. ${ }^{21}$ Future work must be geared towards specifically defining the nature of the "attentional" disorder in chronic fatigue syndrome.

The second major finding was that patients with chronic fatigue syndrome were generally not impaired on tests of memory relative to controls. That is, the chronic fatigue syndrome group did not differ from any of the other groups in visual memory and verbal paragraph recall. This general lack of a memory impairment in chronic fatigue syndrome is consistent with most recent work ${ }^{46}$ but not all. ${ }^{3}$

The only exception to the lack of memory impairment among patients with chronic fatigue syndrome was on the CVLT. The lack of a CVLT impairment in our earlier study ${ }^{5}$ is probably attributed to our stringent inclusion criteria and the resulting more homogeneous sample studied here. In the present study, the chronic fatigue syndrome group displayed significantly more difficulty in the acquisition of information relative to healthy controls on the CVLT; retrieval of the information initially learned did not differ between the chronic fatigue syndrome group and any of the other groups. Taken together, the memory data from the CVLT suggest that patients with chronic fatigue syndrome may have a subtle difficulty in learning verbal material (acquisition), but show intact retrieval from long term storage.
The reduced acquisition of information in the chronic fatigue syndrome group on the CVLT likely reflects a reduced ability to process auditory information, rather than a deficit in storage, consolidation, or retrieval of the memory trace. Another potential explanation lies in the significantly higher depression and anxiety among the chronic fatigue syndrome group relative to healthy controls; the chronic fatigue syndrome and depressed groups did not differ statistically in level of depression or anxiety. Interestingly, the overall pattern of performance of the chronic fatigue syndrome group seemed more similar to the depressed group than any other group on the CVLT. The possibility that depression may have influenced the CVLT performance is supported by recent work, which found that after adjusting for increased depression, the chronic fatigue syndrome group no longer displayed a significant verbal memory impairment. ${ }^{6}$

The third major finding of the present study was that the chronic fatigue syndrome group did not differ from any of the other groups on tasks of "higher order" cognitive functioning. Thus despite their subjective cognitive complaints and increased level of fatigue, depression, and anxiety, patients with chronic fatigue syndrome can perform higher level cognitive tasks at the level of healthy control subjects.

The fourth major finding was that despite the lack of memory or intellectual deficits on neuropsychological tests, the patients with chronic fatigue syndrome had the highest degree of subjective complaints of cognitive impairments. One likely possibility for the perceived level of impaired higher cognitive functions among patients with chronic fatigue syndrome is that they are confusing the difficulty in speed and efficiency of information processing with memory and intellectual or problem solving capability. This hypothesis has important implications for rehabilitation. Proper education and treatment may increase the understanding of the nature of the cognitive difficulties in chronic fatigue syndrome, which may result in improved functional ability.

Our results replicate earlier work ${ }^{22}$ in showing that the depressed group did not differ significantly from controls on the PASAT, trail making test, and digit span. These data suggest that depression alone does not significantly influence performance on tests of complex attention, concentration, and information processing. Similar conclusions have been made from studying depression in other medical populations including those with spinal cord injury ${ }^{23}$ and HIV. ${ }^{24}$ Therefore, the significant difference between chronic fatigue syndrome and controls on the PASAT found in the present study cannot simply be attributed to depression. Thus consistent with the suggestion of Wessely, ${ }^{25}$ the present data show that whereas depression may play a part in explaining the cognitive dysfunction found in chronic fatigue syndrome, it cannot explain all the variance. 
Although performance on individual neuropsychological tests produced few significant differences across groups, the measure of overall neuropsychological performance did show significant differences between the chronic fatigue syndrome and depressed groups and controls. The multiple sclerosis group did not differ statistically from any other group. These data suggest that "subtle" cognitive deficits can be seen in subjects with chronic fatigue syndrome and depression when overall performance of a comprehensive test battery is taken into account. Overall performance shows that chronic fatigue syndrome and depressed patients share mild deficits in effortful cognition.

Difficulties in attention and speed of processing have been correlated with white matter changes in healthy elderly subjects, ${ }^{26}$ and patients with multiple sclerosis ${ }^{27}$ and late stage Lyme disease. ${ }^{28}$ Interestingly, the only three MRI studies examining patients with chronic fatigue syndrome to date ${ }^{29-31}$ show that when MRI findings are present in chronic fatigue syndrome, white matter changes predominate. Taken together, it can be hypothesised that the impaired information processing ability in at least a subgroup of patients with chronic fatigue syndrome may be due to changes in cerebral white matter.

Impaired attention and information processing speed, however, have also been associated with depression and anxiety disorders such as post-traumatic stress disorder. ${ }^{32}$ Yet, heightened "state" or "test" anxiety itself is not necessarily associated with decreased neuropsychological performance. ${ }^{32}$ Further, patients with major affective disorder requiring admission to hospital show similar MRI findings to those observed in chronic fatigue syndrome. ${ }^{33}$ Clearly, further studies are required to clearly delineate the nature of the information processing deficit in chronic fatigue syndrome, and to determine its similarity to or difference from that seen in depression.

We thank Drs John Ottenweller and Steven Ellis for statistica consultation and Mr John Duryee for help in data manipulation and manuscript preparation. This study was supported in part by grant AI-32247 from NIH, establishing a Chronic Fatigue Syndrome Research Center at UMDNI-New Jersey Medical School, Newark NJ; and NIH grant H133P10002-92 to UMDNJ-New Jersey Medical School, and Dep 10002-92 Education, Rehabilitation Services Administration grant H129J10006 to Kessler Institute.

1 Holmes GP, Kaplan JE, Gantz NM, et al. Chronic fatigue syndrome: a working case definition. Ann Intern Med 1988;108:387-9.

2 Riccio M, Thompson C, Wilson B, Morgan DJ, Larient AF. Neuropsychological and psychiatric abnormalities in myalgic encephalomyelitis:

3 Sandman CA, Barron JL, Nackoul K, Goldstein J, Fidler $\mathrm{F}$. Memory deficits associated with chronic fatigue immune dysfunction syndrome. Biol Psychiatry 1993;33: 618-23.

4 Grafman J, Schwartz V, Dale JK, Scheffers M, Houser C Straus SE. Analysis of neuropsychological functioning in patients with chronic fatigue syndrome. $f$ Neurol Neurosurg Psychiatry 1993;56:684-9.

5 Johnson SK, DeLuca J, Fiedler N, Natelson BH. Cognitive functioning in chronic fatigue syndrome. Clin Infect Dis 1994;18(suppl 1):S84-5.

6 Krupp LB, Sliwinski M, Masur DM, Friedberg F, Coyle $\mathrm{PK}$. Cognitive functioning and depression in patients with chronic fatigue syndrome and multiple sclerosis. Arch Neurol 1994;51:705-10.

7 Prasher D, Smith A, Findley L. Sensory and cognitive event related potentials in myalgic encephalomyelitis. f Neurol Neurosurg Psychiatry 1990;1:253-7.

8 Scheffer MK, Johnson R, Grafman J, Dale JK, Straus SE. Attention and short-term memory in chronic fatigue
syndrome patients: An event-related potential analysis. syndrome patients: An even

9 DeLuca J, Johnson SK, Natelson BH. Information processing in chronic fatigue syndrome and multiple sclerosis. Arch Neurol 1993;50:301-4.

10 Schluederberg A, Straus SE, Peterson P, et al. Chronic fatigue syndrome: Definition and medical outcome assessment. Ann Intern Med 1992;117:325-31.

11 Poser CM, Paty DW, Scheinberg L, McDonald WI, Davis FA, Toutellotte WW. New diagnostic criteria for multiple sclerosis: guidelines for research protocols. Ann Neurol 1983;13:227-31.

12 Krupp LB, LaRocca NG, Muir-Nash J, Steinberg AD. The fatigue severity scale: Application to patients with multiple sclerosis and systemic lupus erythematosus. Arch Neurol 1989;46:1121-3.

13 Wechsler D. Wechsler adult intelligence scale-revised, manual. New York: Psychological Corporation, 1981.

14 Wechsler D. Wechsler memory scale-revised, manual. New York: Psychological Corporation, 1987.

15 Beck AT, Ward CH, Mendelson M, Mock J, Erbaugh J. An inventory for measuring depression. Arch Gen Psychiatry 1961;4:561-71.

16 Spielberger $\mathrm{CD}$, Gorsuch $\mathrm{R}$, Lushene $\mathrm{R}$. The state trait anxiety inventory (STAI) test manual. Palo Alto, California: Consulting Psychologists Press, 1983.

17 Mateer CA, Sohlberg MM, Crinean J. Focus on clinical research: Perception of memory function in individuals with closed head injury. Fournal of Head Trauma Rehabilitation 1987;2:78-84.

18 Kirk A. Experimental design: procedures for the behavioral sciences. 2nd ed. Belmont, CA: Brooks-Cole.

19 DeLuca J, Johnson SK. Cognitive impairments in multiple sclerosis: implications for rehabilitation. Neuro Rehabilitation 1993;3:9-16.

20 Shum DHK, McFarland KA, Bain JD. Construct validity of eight tests of attention: comparison of normal and closed head injured samples. The Clinical Neuropsychologist 1990;4:151-62.

21 Gronwall D. Paced auditory serial addition task: A measure of recovery from concussion. Perceptual Motor Skills 1977;44:367-73.

22 Channon S, Baker J, Robertson M. Working memory in clinical depression: an experimental study. Psychol Med 1993;23:87-91.

23 Davidoff GN, Roth EJ, Richards JS. Cognitive deficits in spinal cord injury: epidemiology and outcome. Arch Phys Med Rehabil 1992;73:275-84.

24 Bornstein RA, Pace P, Rosenberger $P$, et al. Depression and neuropsychological performance in asymptomatic HIV infection. Am $\mathcal{F}$ Psychiatry 1993;150:922-7.

25 Wessely S. Chronic fatigue syndrome. $\mathcal{f}$ Neurosurg Neurol Psychiatry 1991;54:669-71.

26 Ylikoski R, Ylikoski A, Erkinjuntti T, Sulkava R, Raininko $R$, Tilvis $R$. White matter changes in healthy elderly persons correlate with attention and speed of mental processing. Arch Neurol 1993;50:818-24.

27 Rao SR. Neurobehavioral aspects of multiple sclerosis. New York: Oxford University Press, 1990.

28 Halperin J, Pass HL, Anand AK, Luft BJ, Volkman DJ, Dattwyler RJ. Nervous system abnormalities in Lyme disease. Ann NY Acad Sci 1988;539:24-34

29 Natelson BH, Cohen JM, Brassloff I, Lee HJ. A controlled study of brain magnetic resonance imaging in patients with fatiguing illnesses. $\mathcal{f}$ Neurol Sci 1993;120:213-7.

30 Buchwald DPR, Cheney DI, Peterson B, et al. A chronic illness characterized by fatigue, neurologic and immunologic disorders and active herpesvirus type 6 infection. Ann Intern Med 1992;116:103-13.

31 Schwartz RB, Garada BM, Komaroff AL, et al. Detection of intracranial abnormalities in patients with chronic intracranial abnormalities in patients with chronic fatigue syndrome: Comparison of MRI imaging and
SPECT. American Roentgen Ray Society 1994;162: SPECT.

32 Puente E, McCaffrey RJ. Handbook of Neuropsychological assessment: a biopsychosocial perspective. New York: Plenum Press, 1992.

33 Swayze VW, Andreasen NC, Alliger RJ, Ehrhardt JC, Yuh WC. Structural brain abnormalities in bipolar affective disorder. Arch Gen Psychiatry 1990;47:1054-9. 